\title{
Supply Chain Simulation in Educational Process
}

\author{
Martin Vojtek ${ }^{1 *}$, Martin Kendra ${ }^{1}$, Jaromír Široký ${ }^{2}$ Katarína Magdechová ${ }^{2}$ and Denis Šipuš ${ }^{3}$ \\ ${ }^{1}$ University of Zilina, Department of Railway Transport, Univerzitna 1, 01026 Zilina, Slovak \\ Republic;Email:martin.vojtek@fpedas.uniza.sk, martin.kendra@fpedas.uniza.sk \\ ${ }^{2}$ University of Pardubice, Department of Transport Technology and Control, Studentska 95, 53210 \\ Pardubice,Czech Republic; Email: jaromir.siroky@upce.cz, katarina.magdechova@upce.cz \\ ${ }^{3}$ University of Zagreb, Faculty of Transport and Traffic Sciences, Vukeličeva 4, 10000 Zagreb, \\ Croatia; Email: denis.sipus@fpz.hr
}

\section{*Corresponding Author: Martin Vojtek}

\begin{abstract}
Logistics is defined as an interdisciplinary science, which deals with coordination, harmonization, connection and optimization of material, product and service flows including flows of information and finance. The main aim of logistics is to satisfy needs of the customer with importance of quality aspect and optimal costs. The paper is focused on practical logistic problems within the company, its suppliers and customers so overall supply chain is analyzed there. The aim of the paper is to provide practical simulation and calculation of selected logistic examples such as procurement, storage and distribution on case studies. These logistic aspects are analyzed in way, how are they explained to students in university educational process on school subjects that deal with logistics in some case. The simulation of storage process is done with specialized software called Byron, which is also used for educational purposes.
\end{abstract}

Keywords: Simulation, procurement, storage, distribution, logistics

\section{Introduction}

Main challenge of logistics is delivering right assortment of products in exact amount, to exact place, in exact time, ecologically and for exact price [1]. Nowadays, the logistics become more popular due to global trends such as widely opened global market, increasing influence of IT sector and ecological aspects, deregulation, standardization, technical revolution, international migration and industrial society. Majority of logistics research and practical technologies are used in manufacturing enterprises and freight transportation. Contemporary challenge of logistics is to ensure the connection among offer and demand, so customers would have got goods and services available in required time and place and with desired quality [2]. 


\section{Procurement Logistics}

Optimization of resources are represented by processes and methods which match the available resources (goods, components, people, finance etc.) with the needs of the organization in order to achieve planned goals. Optimization includes achieving desired results within a set timeframe and budget [3]. When a company is managed by using a systemic approach, resource optimization is strictly linked to the concept of constraints and a systemic vision of the company. Without a systemic vision of the company, we are unable to identify the global effectiveness of resource allocation and we run the risk of using resources mainly to respond to emergencies that daily happens in the different parts of the company [4].

Preconditions for mathematical description of the problem are that demand is constant over the year and each new order is delivered in full when inventory reaches zero. We want to determine the optimal number of units to order so that we minimize the total cost associated with the delivery and storage of the component [5].

Basic formula from the theory of supplies (1):

$$
Q^{*}=\sqrt{\frac{2 * \lambda * c_{d}}{c_{s}}}
$$

To determine the minimum point of the overall logistic costs, calculate the derivative of the overall logistic costs with respect to $\mathrm{Q}$ and assume all other variables are constant. Then set it equal to 0 that provides solution for Q and gives $Q^{*}$ - the optimal order quantity represented by formula (1) [6].

Inputs:

- Considered period: 30 days $=1$ month

- Expected consumption per considered period: 600 kilograms

- Storage costs to one $\mathrm{kg}$ per considered period: $\mathrm{c}_{\mathrm{s}}=0.3 €$

- Constant delivery costs for one delivery: $c_{d}=250 €$

- Overall period: 150 days

Calculation:

$\lambda=$ daily consumption intensity: $600 \mathrm{~kg} / 30$ days $=20 \mathrm{~kg}$ per day

$\mathrm{c}_{\mathrm{s}}=$ storage costs converted to one day: $0.3 € / 30$ days $=0.01 € / \mathrm{kg}$

$\mathrm{Q}^{*}=$ optimal delivery amount: $\sqrt{\frac{2 * \lambda * c_{d}}{c_{S}}}=\sqrt{\frac{2 * 20 * 250}{0,01}}=\sqrt{\frac{2 * 600 * 250}{0,3}}=1000 \mathrm{~kg}$ in one delivery

$\mathrm{C}^{*}=$ optimal delivery cycle: $\mathrm{Q}^{*} / \lambda=1000 \mathrm{~kg} / 20 \mathrm{~kg}$ per one day $=50$ days (new delivery comes every 50 days)

Overall logistic costs: $150 \sqrt{2 * \lambda * c_{d} * c_{s}}=150 \sqrt{2 * 20 * 250 * 0,01}=1500 €$ 
Result of this example can be shown in graph (Fig. 1, below), where $\mathrm{X}$ represents number of deliveries while Y represents amount of costs. Values in the graph are from Table 1 which shows partial results. It can be easily explained on particular example:

Table 1 Numerical values for the graph. Source: authors

\begin{tabular}{llllll}
\hline Delivery costs & \multicolumn{3}{l}{ Storage costs } & \multicolumn{2}{l}{ Overall costs } \\
\hline $\mathrm{X}$ & $\mathrm{Y}$ & $\mathrm{X}$ & $\mathrm{Y}$ & $\mathrm{X}$ & $\mathrm{Y}$ \\
\hline 1 & 250.00 & 1 & $2,250.00$ & 1 & $2,500.00$ \\
\hline 2 & 500.00 & 2 & $1,125.00$ & 2 & $1,625.00$ \\
\hline 3 & 750.00 & 3 & 750.00 & 3 & $1,500.00$ \\
\hline 4 & $1,000.00$ & 4 & 562.00 & 4 & $1,562.00$ \\
\hline 5 & $1,250.00$ & 5 & 450.00 & 5 & $1,700.00$ \\
\hline 6 & $1,500.00$ & 6 & 375.00 & 6 & $1,875.00$ \\
\hline 7 & $1,750.00$ & 7 & 321.43 & 7 & $2,071.00$ \\
\hline 8 & $2,000.00$ & 8 & 281.25 & 8 & $2,281.00$ \\
\hline 9 & $2,250.00$ & 9 & 250.00 & 9 & $2,500.00$ \\
\hline
\end{tabular}

When there is only one delivery per considered period, delivery costs are $250 €$. Storage costs are average value of supply quantity multiplied by the period. For instance, the period lasts 150 days and with one delivery, there is $600 \mathrm{~kg} * 5$ months $=3000 \mathrm{~kg}$ of supplies at the beginning and $0 \mathrm{~kg}$ at the end, therefore average storage costs are $1500 \mathrm{~kg}$ (average amount of supplies) * 150 days $($ period $) * 0,01 €($ daily storage costs per one $\mathrm{kg})=2250 €$. Overall costs $=$ Delivery costs + Storage costs.

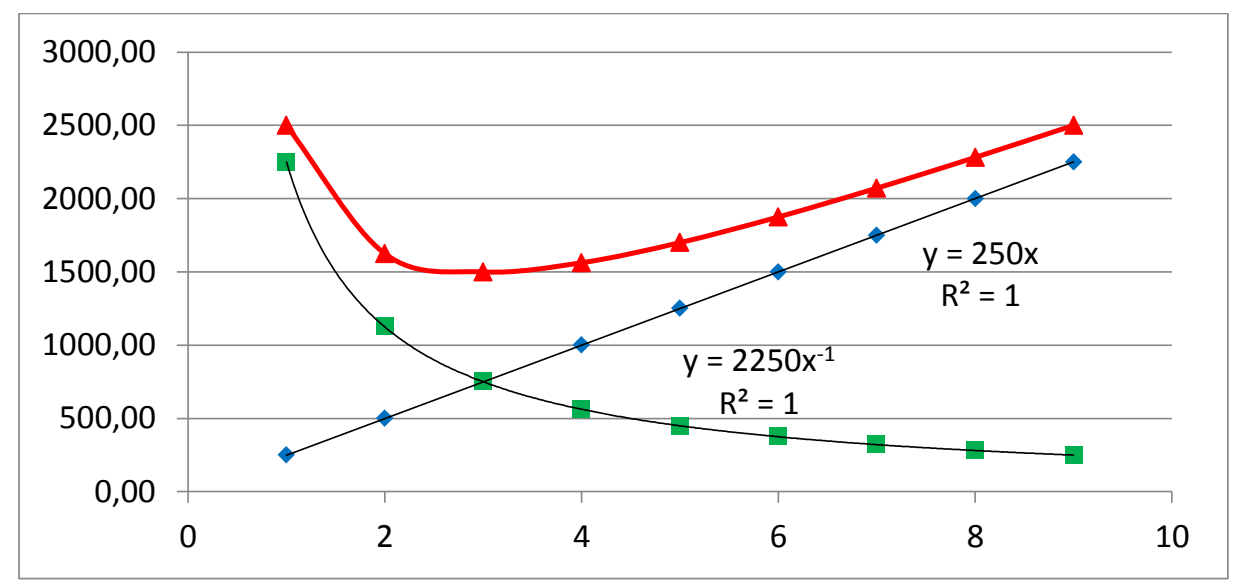

Fig. 1 Graph with results. Source: authors

\section{Storage Process Simulation}

Warehousing - the process of storage can be explained by practical simulation in specialized software called Byron [7]. Firstly, the warehouse infrastructure must be designated (see Fig. 2). 


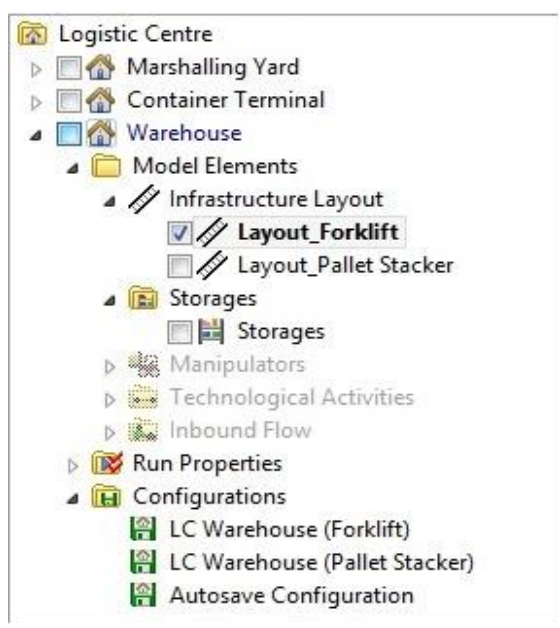

Fig. 2 Selection of the warehouse infrastructure. Source: authors from Byron

Next step is set of material flows in the warehouse. All material flow inputs and outputs have to be counted in the simulation to reach the exact result (see Fig. 3).

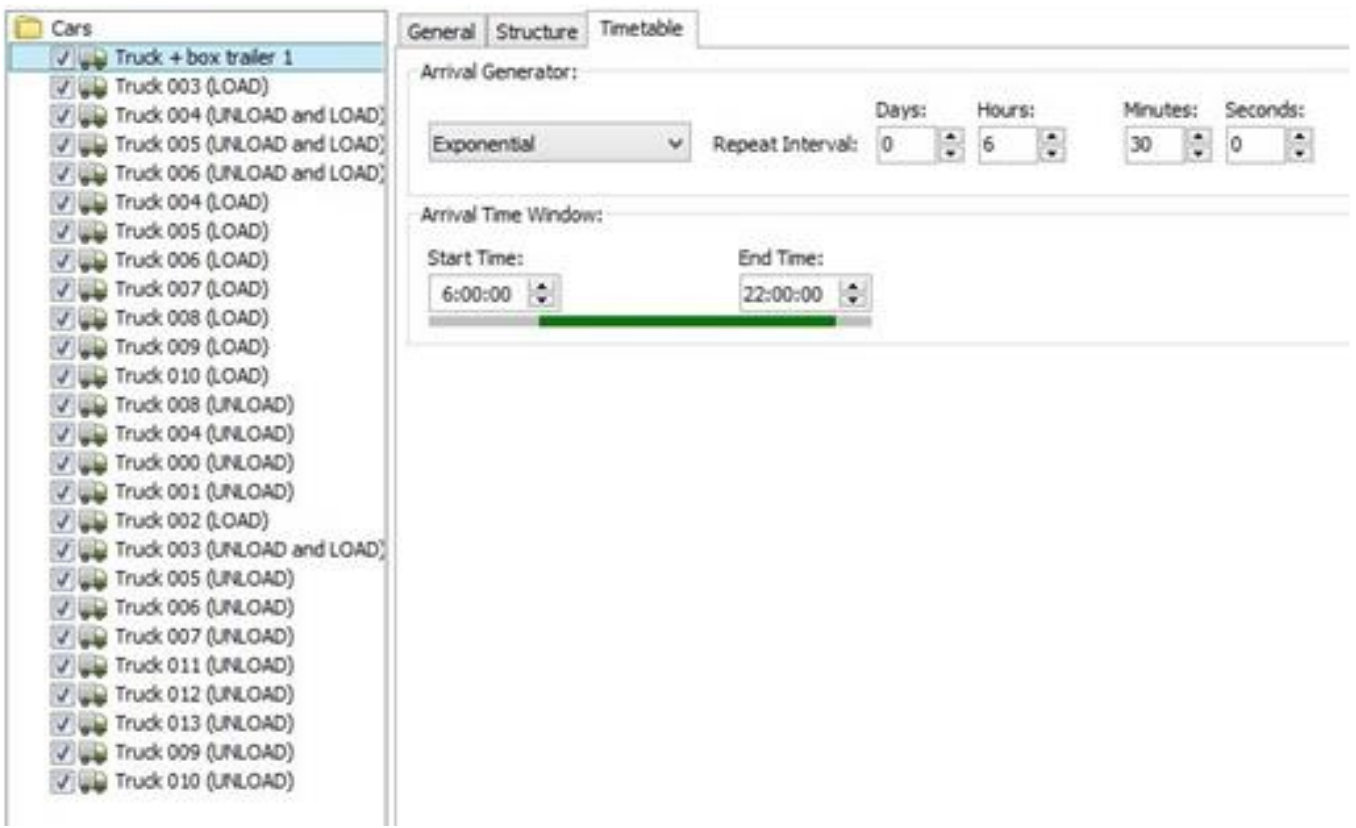

Fig. 3 Material flow settings. Source: authors from Byron

Simulation results show us all aspects of warehousing but they are very dependent on all input parameters (see Fig. 4). Some change in these parameters could significantly influence the result.

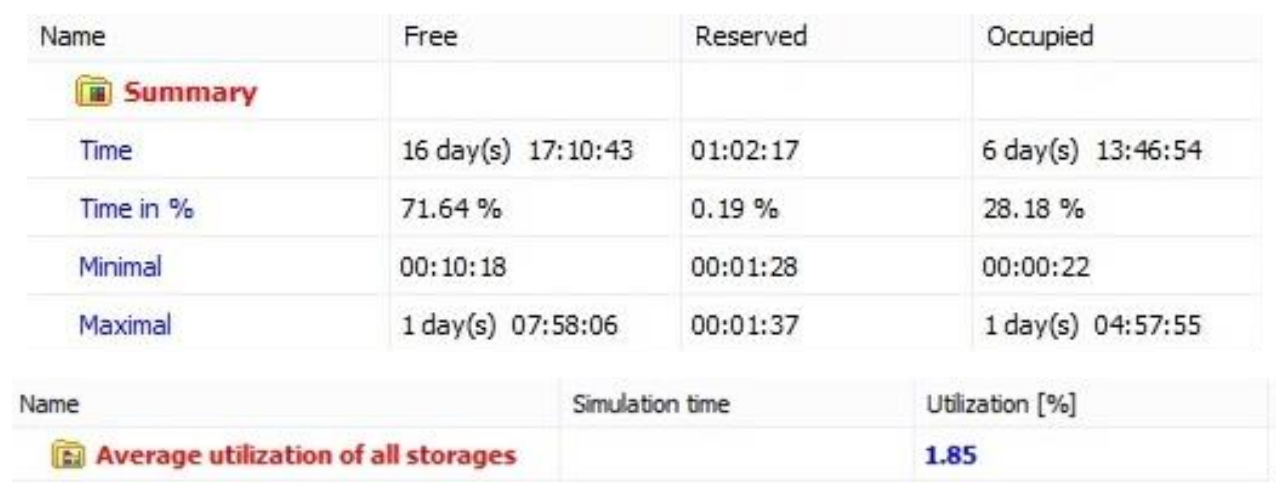

Fig. 4 Utilization of gateways and storage area. Source: authors from Byron 
Functionality of software Byron is not provided for ordinary user. Byron provides only simulation process with results depending on inputs and there are not any background of calculations and used know-how, because it is specialized software created for improving educational process. In the practical example, the result value of storage area utilization is very small, because majority of components that are delivered to the warehouse are immediately moved to production part directly. The warehouse is designated to preclusion of production failure [8].

\section{Distribution Logistics}

Distribution is the process of making a product or service available for the customer who needs it. This can be done directly by the producer or service provider, or using indirect channels with distributors or intermediaries [9]. There are three approaches to distribution:

Mass distribution (also known as intensive distribution): For example, snack foods and drinks are sold at outlets including supermarkets, convenience stores, vending machines, cafeterias and others. These products must be transported in large quantities [10].

Selective distribution: It can be explained on some practical examples. A manufacturer of premium electrical goods may choose to agree with stores and independent outlets that can provide added value service level required to support the product. Other example may be that some prestige brands of cosmetics and skincare want that sales staff should be trained to use the product range [11].

Exclusive distribution: In exclusive distribution, a manufacturer chooses to agree with one intermediary or one type of intermediary. Advantage of this agreement is that the manufacturer gains greater control over the distribution process. In exclusive arrangements, the distributor is expected to work closely with the manufacturer and gain value to the product through service level, after sales care or client support services [12].

Distribution can be explained mathematically by solving the traveling salesman problem. TSP asks the following question: "Given a list of cities and the distances between each pair of cities, what is the shortest possible route that visits each city and returns to the origin city?" The problem was first formulated in 1930 and is one of the most intensively studied problems in optimization [13]. It is used as a benchmark for many optimization methods. Even though the problem is computationally difficult, a large number of heuristics and exact algorithms are known, so that some instances with tens of thousands of cities can be solved completely and even problems with millions of cities can be approximated within a small fraction of $1 \%$ [14]. The most direct solution would be to try all permutations (ordered combinations) and see which one is the cheapest. The running time for this approach lies within a polynomial factor of $n$ ! (Factorial of the number of cities) so this solution becomes impractical even for only 20 cities. Various heuristics and approximation 
algorithms, which quickly yield good solutions have been devised. Modern methods can find solutions for extremely large problems (millions of cities) within a reasonable time which are with a high probability just 2-3\% away from the optimal solution [15].

\section{Conclusion}

The logistics is a key function of the company if the goal is to make right amount of products or services, which must be delivered to correct place in accurate time with required quality to all customers. It is necessary to present this main goal of the logistics in educational process to explain all related aspects and accomplish comprehensibility of logistics for students. The paper consists of basic parts of the supply chain - procurement, storage and distribution. These parts are described by practical examples and simulation.

\section{Acknowledgments}

The paper was supported by the project EUREKA E!11214 - EPLOS - innovation across borders "European portal of logistics services" at Faculty of Operations and Economics of Transport and Communication, University of Žilina, VYSSKUMU' A ŠPORTU
SLOVENSKE] REPUBLIKY Slovakia.

\section{References}

[1] Kudlac, S., Majercak, J. \& Majercak, P. (2017). Comparison of Different Variants of Logistics Chain with the Use of Air Transport Using the Software Application. Transportation research Procedia. 28, 45-50. DOI: 10.1016/j.trpro.2017.12.167.

[2] Majercak, J., Kudlac, S. \& Panak, M. (2016). Sustainable and Economically Efficient FivePoint Supply Chain Management. Transport Means - Proceedings of the International Conference. 65-70.

[3] Chovancova, M. \& Klapita, V. (2017). Modeling the Supply Process using the Application of Selected Methods of Operational Analysis. Open Engineering. 7(1), 50-54. DOI: 10.1515/eng-2017-0009.

[4] Figlus, T., Gnap, J., Skrucany, T. \& Szafraniec, P. Analysis of the Influence of Different Means of Transport on the Level of Traffic Noise. Scientific Journal of Silesian University of Technology - Series Transport. 97, 27-38, DOI: 10.20858/sjsutst.2017.97.3.

[5] Stoilova, S. (2016). Study of the Efficiency of Motorail Trains as a Factor in Transport Development. SGEM 2016, BK 2: Political Sciences, Law, Finance, Economics and Tourism Conference Proceedings. 5, 627-634. 
[6] Grubbstrom, R. W. (1995). Modelling production opportunities - an historical overview. International Journal of Production Economics. 41(1-3), 1-14. DOI: 10.1016/09255273(95)00109-3.

[7] Kudlac, S., Stefancova, V. \& Majercak, J. (2017). Using the SAATY Method and the FMEA Method for Evaluation of Constraints in Logistics Chain. Transbaltica 2017: Transportation Science and Technology, Book Series: Procedia Engineering. 187, 749-755. DOI: 10.1016/j.proeng.2017.04.433.

[8] Stopka, O., Chovancova, M., Lizbetin, J. \& Klapita, V. (2016). Proposal for Optimization of the Inventory Level Using the Appropriate Method for its Procurement. Nase More. 63(3), 195-199.

[9] Cerna, L. \& Masek, J. (2015). The Proposal the Methodology of the Supply Chain Management in Transport and Logistic Company. Transport Means 2015, PTS I and II, Book Series: Transport Means - Proceedings of the International Conference. 567-570.

[10] Chovancova, M. \& Kapita, V. (2016). Draft Model for Optimization of the Intermodal Transport Chains by Applying the Network Analysis. Transport Means: Proceedings of the International Conference. 112-116.

[11] Gasparik, J., Luptak, V. \& Mesko, P. (2016). New Methodology for Assesing Transport Connections Depending on the Integrated Transport Network. Proceedings of the Thirs International Conference on Traffic and Transport Engineering (ICTTE). 388-392.

[12] Nedeliakova, E., Nedeliak, I. \& Majercak, P. (2014). Research of Services Quality after the End of Transportation in Railway Freight Transport. In: 2nd International Conference on Management Innovation and Business Innovation (ICMIBI 2014), Book Series: Lecture Notes in Management Science, 44, (pp. 54-61). DOI: 10.5729/lnms.vol44.54.

[13] Chovancova, M., Stopka, O. \& Klapita, V. (2017). Modeling the Distribution Network Applying the Principles of Linear Programming. Transport Means - Proceedings of the International Conference. 73-77.

[14] Dolinayova, A., Camaj, J. \& Kanis, J. (2017). Charging Railway Infrastructure Models and their Impact to Competitiveness of Railway Transport. Transport Problems. 12(1), 139-150. DOI: $10.20858 / \mathrm{tp} .2017 .12 .13$.

[15] Stopka, O., Cerna, L. \& Zitricky, V. (2016). Methodology for Measuring the Customer Satisfaction with the Logistics Services. Nase More. 63(3), 189-194. 